\title{
Impact of phenolic compound as activators or inhibitors on the enzymatic hydrolysis of cellulose
}

\author{
Ioanna Stamogiannou ${ }^{1}$, John Van Camp ${ }^{2}$, Guy Smagghe ${ }^{1}$, Davy Van de Walle ${ }^{1}$, Koen \\ Dewettinck $^{1}$, and Katleen Raes ${ }^{1}$ \\ ${ }^{1}$ Ghent University \\ ${ }^{2}$ Universiteit Gent
}

July 15, 2020

\begin{abstract}
The influence of phenolic compounds on the enzymatic hydrolysis of cellulose was studied in depth using spectrophotometric techniques, adsorption analysis and Scanning Electron Microscopy (SEM). In this paper, both possible interactions between phenolic compounds and the enzyme or the substrate were investigated with the use of various phenolic compounds, cellulase from T. reesei, and Avicel. Three classes of phenolic compounds have been identified, based on their effect on the hydrolysis of cellulose: inhibitors (quercetin, kaempferol, cinnamic acid, luteolin, ellagic acid), non-inhibitors, and activators (ferulic acid, syringic acid, sinapic acid, vannilic acid). Secondly, since various structures of phenolic compounds were investigated, it was deduced that an -OCH3 group was necessary for the activating effect. Finally, based on the adsorption spectra and SEM images, a different way of adsorption (either on the enzyme or on the substrate) was noticed, depending if a phenolic compound was an inhibitor or an activator.
\end{abstract}

\section{Hosted file}

final.docx available at https://authorea.com/users/342934/articles/469707-impact-ofphenolic-compound-as-activators-or-inhibitors-on-the-enzymatic-hydrolysis-of-cellulose 